\title{
EDITORIAL
}

\section{Highlights of special issue on forestry}

\author{
Shougong ZHANG (凶) \\ Chinese Academy of Forestry, Beijing 100091, China
}

Forests are a major component of terrestrial ecosystem, therefore they are an invaluable asset that has been bestowed by nature on mankind. Forests enjoy the reputation of "Lungs of the Earth" because they provide residence for both humans and other forms of life, and have multiple functions, including fixing carbon and releasing oxygen, retaining water sources, protecting and nurturing soil, purifying air, breaking wind and fixing sand, accumulating nutrient substances and conserving biodiversity. Due to these fundamental reasons, they are cherished by human beings. In the evolution of human society, however, we often find examples where rapid reductions in forests and ecological destruction have led to decline or even extinction of civilizations. The civilizations in Mesopotamia and ancient Loulan Kingdom fully illustrated the importance of forests in human social development. Science and technology are highly important for sustainable forestry development. As such, collected in this special issue are some important endeavors and innovative progress of research in key aspects of forest science and engineering.

Strengthening ecological civilization is extremely important for China to build a prosperous society in a holistic way, to realize the sustainable economic and social development, and the rejuvenation of the country. Shen explained and discussed the concept of ecological conservation and construction in China, reviewed the historical background of ecological activities in China and their major achievements in the past, provided a comprehensive idea of various types of ecological control activities, and defined the scope of some ecological terms used in China, such as ecological protection, conservation, remediation (rehabilitation), and restoration, as well as the re-establishment of new ecosystems. Finally, Shen proposed five guidelines for promoting the implementation of ecological conservation and construction in China based on the two important governmental documents related to the development of ecological civilization, which are very important to guide national ecological conservation and construction.

The development of a eucalypt industry in China has made important contributions to both the national economy and the livelihoods of a substantial number of Chinese people. In China, eucalypts contribute up to $25 \%$ of national wood production from only $2.2 \%$ of forest land. This eucalypt industry has become a complex, multifaceted industry including seedling propagation, fertilizer production and supply, plantation silviculture, harvesting and transport, wood processing for products, as well as bioenergy production and various forest byproducts. The combined value of output of eucalypt industry is about 300 billion CNY per year. In this special issue, Xie et al. reviewed six topics of recent advance in eucalypt research in China, which included advanced propagation technology, genetic resources and breeding, targeted silviculture, eucalypt disease and pest management, enhancing plantation ecology and sustainability, and wood processing and byproduct technology. This highlights the importance of R\&D which has greatly facilitated expansion and proliferation of all facets of the eucalypt industry in China.

Birch (Betula platyphylla) is a valuable broadleaf tree species, which is widely distributed in 14 regions of China. Therefore, the discovery and in depth exploration of birch geographical variation, provenance regionalization and molecular biotechnology will contribute greatly to both theory and application. Yang highlighted several aspects of the progress of research in genetic improvement of $B$. platyphylla, such as germplasm resource collection, geographic variation patterns, provenance division and superior provenance, interspecific hybridization, intraspecific hybridization and parallel crosses, as well as systems of asexual propagation. This progress has provided a model and data for future forest genetic improvement and applied research.

Received December 1, 2017; accepted December 4, 2017

Correspondence: shougong.zhang@caf.ac.cn

(c) The Author(s) 2017. Published by Higher Education Press. This is an open access article under the CC BY license (http://creativecommons.org/licenses/by/4.0) 
Desertification is a serious threat to ecological security and sustainable development faced by China and the world. During the past decades, China has made remarkable achievements in combating desertification and achieved land degradation neutrality. Bao et al. analyzed China's "eight-column four-beam" strategy and associated actions for combating desertification, including government steering, public participation, scientific support and legislative guarantee. A "four-medicine" approach, i.e., developing a UNCCD protocol for unified global compliance, establishing a global desertification observation network, compiling a global natural desert heritage inventory, and fostering global cooperation for combating desertification, was proposed for global desertification governance. China's experience is valuable for other parties of UNCCD to combating desertification, and the proposed solution is helpful to achieve land degradation neutrality for the world.

The fundamental goal of forestry development is to achieve sustainable forest management. Although there are many ways to promote sustainable forest management, forest certification is a particularly effective market-based instrument for this purpose. Lu et al. highlighted the progress in forest certification in China, and analyzed the challenges due to the ban on commercial logging in natural forests and opportunities flowing from increased demand for certified non-timber forest products that benefit local communities who depend on forests for the goods and services they provide. Likely government procurement and subsidy policies will be highly conducive to accelerate forest certification in China, thus rapidly promoting sustainable forest management.

Repetitive elements are abundant in plant genomes. Identifying repetitive elements in the transcribed region of perennial woody plant genomes would enable us to develop novel molecular breeding tools for the genetic improvement of important agronomic traits. To achieve this goal, Biswas et al. screened the repetitive elements including tandem repeats (TRs) and transposable elements (TEs) based on non-redundant EST data sets of 11 Citrus spp. They further compared the densities and length characteristics of different repeat types and unit size ranges. Their findings would provide valuable resource for the development of genetic tools such as molecular markers, and facilitate the genetic improvement of highly important traits in citrus.

The extensive development of eucalypt plantations in China and the relatively limited numbers of clones planted has resulted in the increase of numerous pests and pathogens that have caused escalating levels of damage. The genus Quambalaria includes several important pathogens of species of eucalypts, mainly causing leaf and shoot blight in Australasia, Africa, southern Africa and Europe. Based on morphological structures and phylogenetic analyses with DNA sequence data, Chen et al. identified three species of Quambalaria from eucalypt plantations in southern China. These results confirm that Quambalaria species are widespread in areas of China where eucalypts are grown, and they are likely to become more important in commercial forestry in the future.

High-quality climate data are essential for conducting climate-change impact analyses. Low-to-moderate resolution gridded climate data currently available are not adequate for climate-impact modeling at local scales to develop adaptive forest management strategies. Wang et al. developed a computer software package, ClimateAP, which used the best available gridded climate data as baseline data and applied dynamic local downscaling algorithms to generate scale-free climate data for any specific locations in the Asia-Pacific region for historical and future periods. This tool makes the access to climate variables (i.e., true environmental variables) as easy as for geographical variables (i.e., substitutes of environmental variables) and thus may change the way scientists design experiments and analyze results.

The most commonly used $\mathrm{TiO}_{2}$ photocatalysts could only response to the UV light spectrum, which greatly limits its application in practice. Hence, the modification of $\mathrm{TiO}_{2}$ is needed for using solar irradiation or interior lighting efficiently. $\mathrm{Li}$ et al. presented a simple method by using Papilio paris butterfly wings as biotemplates, coating with $\mathrm{TiO}_{2}$ films, calcination in air, and finally replicating the hierarchical structure of butterfly wings. $\mathrm{TiO}_{2}$ with hierarchical structures was of considerable interest for high specific surface area, and thus a higher photocatalytic performance was achieved. Furthermore, the doping of $\mathrm{C}$ originating from wings in the $\mathrm{TiO}_{2}$ semiconductor could extend the photoresponsiveness to visible light. Their strategy provides a simple method to fabricate a high-performance photocatalyst, which enables the simultaneous control of the morphology and carbon element doping.

Ginkgolic acid, which is considered a mutagen and carcinogen, causing skin, mucous membrane and other allergic inflammatory responses, is abundant in Ginkgo biloba sarcotesta with the highest levels reported from 5\% to $13 \%$. However, ginkgolic acid can also be extracted from ginkgo sarcotestae and used as a biological pesticide. Therefore, reasonable utilization, selective degradation and removal of ginkgolic acid would improve the safety of G. biloba extracts and ginkgo food. Li et al. optimized the extraction method of ginkgolic acids from G. biloba sarcotestae and established an effective degradation method, with high catalytic efficiency and safety, to remove ginkgolic acids by laccases. These results lay the foundation for research on and application of biological enzymes for detoxification of $G$. biloba extracts.

Biomass is one of the most utilized sources of renewable energy worldwide, and its use in modern, high-efficiency bioenergy and transportation biofuel applications is increasing. However, little work has considered the conditions that might influence the allocation of biomass to either bioenergy or biofuel applications. Hu et al. assessed the potential bioenergy/biofuel use of four major world biomass-consuming countries, namely Brazil, Denmark, Sweden and the USA. 
The findings of each country were systematically compared with respect to the importance of biomass in the energy mix, the dominant biomass applications, the status of biomass competition, and the importance of each country's policies in biomass allocation. The results indicate that there is no competition for biomass between bioenergy and biofuel applications. It is also evident that good national policies are essential as these provide a more stable structure for bioenergy and biofuel development.

Early selection is an important method to shorten breeding period of trees, especially for conifers. To improve wood properties, Sun et al. examined the age-related trends in genetic parameters for wood properties in Larix kaempferi clones, and determined the optimal selection age for these traits. They proposed a comprehensive early selection strategy that involved selection based on nursery rooting ability, phenology, growth traits and wood properties. Their work lays a solid foundation for larch clonal breeding.

The demand for forest biomass as feedstock for heat and power generation has increased considerably at a global scale. In Sweden, more than half of the feedstock input for the production of district heat is forest biomass. Athanassiadis et al. compared several supply chains and presented marginal cost curves for logging residues and stumps for Swedish conditions. They found that procurement costs for logging residues has started from 60 EUR per oven-dried tonne and stumps from 90 EUR per oven-dried tonne. These costs increase rapidly the further away the harvested area is from a heat and power plant. In the case that the total potential of logging residues, stumps and small diameter trees in Sweden were actually utilized for production of heat then all demand for bioenergy from the district heating sector would have been satisfied.

In China, forestry is apart from agriculture sector, with the same as water conservation. Forestry also covers a wide range of diverse disciplines, and covers an even wider range of globally important topics, such as climate change mitigation and adaptation, wildlife protection and biodiversity conservation. Consequently, it is a huge challenge to cover all these disciplines and topics in this special issue. Nevertheless, we sincerely hope that the reader will enjoy the papers presented in this collection, which are to a degree representative of recent progress across the research in the forestry sector. Lastly, I greatly appreciate the endeavors of all contributors in this collection. It would have been impossible to present this special issue without their full support.

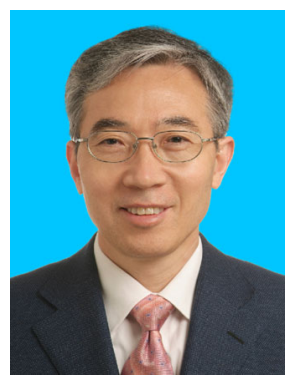

Shougong Zhang, guest editor of this special issue, received a bachelor degree from Anhui Agricultural University, China in 1982 and a doctor degree from Beijing Forestry University, China in 1990. Being an expert on silviculture, he serves as academician of the Chinese Academy of Engineering and president and professor of the Chinese Academy of Forestry. He has been dedicated to the applied and basic research as well as technical development of genetic improvement, and directed breeding and management of larch species. He has made fruitful achievements in the research fields of planted forest cultivation and sustainable forest management. He received three second-class prizes of the National Science and Technology Progress Award, two first-class prizes and one second-class prize of Ministerial- and Provincial-level Science and Technology Progress Award, and one prize of China Youth Science and Technology Award. He has published 263 academic articles (Among which, 42 were published in SCI journals. He was the first author or the corresponding author of 98 articles.) and 7 monographs. He obtained one overseas invention patent (issued by Canada) and 13 national invention patents. He led the development of one national standard and eight forestry sector standards. He has supervised $43 \mathrm{PhD}$ graduates. He served as the principal scientist of the National Basic Research Program of China (973 Program), member of the expert panel of agricultural sector for the National High-tech R\&D Program (863 Program), member of the national committee of the $5^{\text {th }}$ National Congress of the China Association for Science and Technology, board member of the International Union of Forest Research Organizations, executive director of Asia-Pacific forestry advisory group, and vice chair of the presidium of the $11^{\text {th }}$ World Forestry Congress. Now he works as vice president of the Chinese Society of Forestry, president of Afforestation Association of the Chinese Society of Forestry, and chairman of the National Technical Committee for Standardization of Sustainable Forest Management and Forest Certification. 